\section{LOS MUNDOS LEJANOS DE ÁNGELA GRASSI: HISTORIA, LEYENDA Y MORAL}

\author{
Concepción Núñez Rey \\ Universidad Complutense de Madrid \\ cnunezre@ccinf.ucm.es
}

\section{ÁNGELA GRASSI'S DISTANT WORLDS: HISTORY, LEGEND AND ETHICS}

Cómo citar este artículo/Citation: Núñez Rey, C. (2014). “Los mundos lejanos de Ángela Grassi: historia, leyenda y moral". Arbor, 190 (767): a140. doi: http://dx.doi.org/10.3989/ arbor.2014.767n3011

Recibido: 3 julio 2013. Aceptado: 6 abril 2014.

RESUMEN: El presente estudio se propone descubrir las claves ideológicas y formales en que se funda la obra literaria publicada por Ángela Grassi (1823-1883) bajo la forma de artículos en prensa. De su extensa producción, aparecida en las diversas revistas de su tiempo, en especial en las femeninas, hemos acotado más de medio centenar de artículos publicados en El Correo de la Moda, la revista en que la autora colaboró más asiduamente desde 1866 y que dirigió desde 1867 hasta su muerte. Su obra, de estirpe romántica, se aleja de la realidad de su época para huir hacia tiempos históricos o legendarios en los que busca modelos útiles para una enseñanza moral; todo ello revestido de una gran riqueza literaria.

PALABRAS CLAVE: Ángela Grassi; El Correo de la Moda; prensa española del siglo XIX; prensa femenina; revistas femeninas; escritoras isabelinas; escritoras románticas; artículos literarios.
Copyright: (C) 2014 CSIC. Este es un artículo de acceso abierto distribuido bajo los términos de la licencia Creative Commons Attribution-Non Commercial (by-nc) Spain 3.0.

ABSTRACT: This study sets out to uncover the ideological and formal keys of the literary work published by Ángela Grassi (1823-1883) in the form of press articles. Of her extensive production, which appeared in various magazines of her time, particularly women's magazines, we have annotated over fifty articles published in El Correo de la Moda, the magazine to which Grassi contributed most assiduously from 1866 onwards, and which she ran from 1867 until her death. Her work, romantic in nature, escapes the reality of her age in historical or legendary times in which she looks for useful models for moral education; all wrapped in a rich literary style.

KEYWORDS: Ángela Grassi; El Correo de la Moda; Spanish press of the 19th century; feminine press; feminine magazines; women writers during the reign of Isabella II; romantic writers; literary articles. 


\section{LA LEJANÍA}

La lejanía aludida en el título significa de modo general el rasgo destacado que impregna la obra literaria de Ángela Grassi, en especial, de ella fluye el gran caudal de sus artículos periodísticos, objeto de nuestro estudio ${ }^{1}$.

Entendemos siempre lejanía como distancia objetiva del aquí y el ahora, de la realidad que nos circunda, del presente en que vivimos, pero aún hallaremos otros matices más subjetivos que ensanchan esta idea inicial.

De forma patente, nuestra autora no se aproxima con sus artículos a su tiempo y espacio vitales sino en muy contadas ocasiones, y solo con levísimas alusiones, como si su pensamiento rebotase en la realidad próxima y saliese repelido.

Así, los escenarios de sus artículos nos alejan de Madrid, la ciudad en que Grassi residió durante cerca de tres décadas y donde desplegó su fecunda labor periodística. De igual modo, siempre están ausentes los espacios observados, descritos como fruto de la experiencia directa; tan solo nos ofrece algunas pinceladas de ciudades y paisajes españoles realmente visitados. En su mayoría, son espacios conocidos de forma erudita o libresca, evocados mediante escasos trazos y embellecidos con la imaginación. En ocasiones, tan solo se trata de espacios aludidos, y muchos son exóticos, sean de los países de Oriente, hasta China, sean de las regiones del Norte, hasta las polares.

En cuanto a la distancia en el tiempo, nos descubre el verdadero paraíso literario de la autora, los mundos del pasado, de cualquier pasado, remontándose a las más antiguas civilizaciones, que ella convierte en su verdadera realidad.

Tal posición de huida del presente nos remite a la corriente romántica, al menos, a uno de los anchos brazos de esa corriente que dominó el pensamiento y el arte en la primera mitad del siglo XIX. Pero la obra periodística de Ángela Grassi se despliega a lo largo de la segunda mitad del siglo, un tiempo en que triunfa el positivismo y en que la observación de la realidad se convierte en ley artística. Vemos así un nuevo matiz de la lejanía: la obra de la autora se desenvuelve contracorriente de las nuevas tendencias y se instala en la concepción literaria de un tiempo ya pasado.

De igual modo, un desajuste tan profundo con la realidad nos obliga a pensar en la característica insatisfacción de los románticos, en su inquietud o desazón. Pero no es el caso de Grassi; su universo mental es equilibrado y estable; en realidad, el pasado es su mundo ideal porque es acabado, inmutable, perdurable; frente al presente dinámico e inquietante.

Recordemos aún otro matiz de la lejanía en la obra de la autora: la fuerza de lo imaginario, incluso de lo maravilloso, frente al rigor de la referencia histórica, de la precisión erudita. Aunque, justamente, lo que se pierde en verdad histórica se gana en valor literario, y en ello reside la fuerza creativa de Ángela Grassi, constructora de un extenso universo legendario, fabuloso, mítico, expandido por las más lejanas épocas y culturas.

\section{COSMOVISIÓN. UN UNIVERSO PERFECTO}

No se trata de un universo inestable, a pesar de ello, no queda reducido a un puro divagar por el tiempo, sino que aparece organizado por una estructura coherente y perfecta en cuyo centro ordenador se sitúa Dios, creador de todo cuanto existe, de todas las perfecciones de la Naturaleza y de la perfección del hombre, hecho a su semejanza. Dios, aludido con frecuencia como la Providencia que protege amorosamente a sus criaturas haciendo triunfar el bien, la verdad y la belleza. La idea de Dios se expresa con múltiples y bellísimos nombres agrupados en cuatro grandes conceptos. Como Dios Todopoderoso es "Rey de Reyes", "el Eterno", "el Altísimo", el "trono del Eterno", "Divinidad sublime e infinita", "Diestra oculta que gobierna el universo", "esplendoroso sagrario del Eterno". Como Dios Creador es el "Supremo autor", "el pincel eterno", "Hacedor supremo", "Artífice supremo". Como juez es: "Árbitro supremo", "Juez supremo", "Dios de inescrutable justicia", "juez justo", "juez incorruptible". Y como redentor es: "Jesucristo", "Salvador divino", "Redentor divino", "el Crucificado", "el mártir de las alturas infinitas", "el Santo Cordero inmaculado", "Consolador infinito"2.

A la presencia de Dios, latente pero constante en la obra de Grassi, se corresponde su fe firme e incuestionable, la "Santa fe" $(626, \text { p. } 3)^{3}$ salvadora y consoladora, y profesada por todas las figuras que animan sus escritos. A veces es expresada con bella plasticidad: "Esta voz, que resuena en los trinos de los pájaros, en los murmurios de las fuentes, en los gemidos de los ecos, en las armonías del cielo, grita sin cesar a mi alma: ¡Ama y bendice en las criaturas al Supremo autor de cuanto existe!" (664, p. 314).

Los personajes de Grassi reciben una energía, a veces, heroica, gracias a "su fe profunda en Dios" (667, p. 338). Otras veces, la fe es triunfadora en los hom- 
bres a pesar de las circunstancias adversas, como los lapones, enfrentados a una naturaleza hostil: "el lapón alza todos los días las manos al cielo, y bendice a la Providencia, exclamando que su país es el más bello de la tierra" (652, p. 219).

Por otra parte, en sus frecuentes viajes al pasado, la autora se encuentra con divinidades de las culturas antiguas, sobre las que siempre prevalece Dios: "Majestad, oculta, sabia e infinita [...] el Supremo autor de cuanto existe" (664, p. 314).

O se encuentra con una religión primitiva, como la de los guanches, a la que acoge destacando sus valores positivos: "Adoraban [...] a la Naturaleza, y se tenía por un sacrilegio irremisible manchar sus aras con la sangre de ningún ser viviente [...] la paz, el amor y la fraternidad reinaban allí sin obstáculos" (636, p. 91).

En uno de los escasos episodios que sitúan a la autora en la realidad presente, se encuentra con "una niña de cuatro años desgreñada y andrajosa", que recoge alfileres con cuya venta ayuda a comprar aceite para la Virgen ("de los alfileritos"), y a la que Grassi aconseja: "pobre niña, guarda siempre esa hermosa fe del alma" (646, p. 171).

Su fe se dirige "al que vino a iluminar con una luz tan suave el imperio moral del universo" (631, p. 42), y en ello funda su sentir religioso: fe que trae luz, consuelo y sentido a la vida humana. Solo en una alusión nos da la idea de un Dios implacable con sus criaturas, pero no es más que una posibilidad: "Sin duda Dios no debió echar su maldición sobre aquellas islas afortunadas" (636, p. 91).

Desde tan sólido edificio, toda su obra se despliega en dos direcciones fundamentales. Por una parte, la celebración gozosa, a veces exaltada, de todo lo creado en un emotivo canto a la grandiosidad de la naturaleza y a la grandeza humana. En tan perfecta armonía de vínculo, toda obra o "industria" creada por la mano del hombre, en especial la que por su utilidad haya contribuido a su progreso, es también objeto de celebración por ser de inspiración divina, porque toda facultad humana procede de Dios.

Con total coherencia, Ángela Grassi desarrolla su obra literaria dentro del marco estable de esta concepción religiosa, fundamento que da orden, sentido y valor a la existencia, frente al caos y el azar.

La otra dirección que siguen sus escritos es la corriente más caudalosa y responde a la necesidad de la enseñanza moral ${ }^{4}$. Se origina en su visión sagrada del hombre y en su sincero amor a las criaturas, en la fe en su grandeza y en la esperanza de que el hombre se eleve sobre sí mismo para buscar la perfección de espíritu. Pero el hombre, dotado de libre albedrío (651, p. 210), puede caer en la imperfección y destruir la armonía de lo creado, por ello se hace imprescindible conducirle por el camino de la virtud, ofrecerle una educación moral que le ayude a regresar a la pureza primigenia.

Es la meta perseguida por Ángela Grassi en sus diversos escritos. Una inmensa labor educadora en cuya complejidad nos vamos a detener más tarde. ${ }^{5}$

Aunque se fundamente en la religión católica, la enseñanza que divulga la autora no es religiosa; no explica dogmas teológicos, ni ritos eclesiales. Su deseo es ayudar a sostener la fe y orientar las conductas. A ello se suma su criterio equilibrado y lúcido, que defiende la devoción a través de figuras ejemplares, pero previene de los excesos ${ }^{6}$, incluso lamenta el poder destructor del fanatismo religioso. ${ }^{7}$

Al mismo tiempo, mediante uno de sus modelos históricos, se inclina por la separación del poder religioso y el civil, que, como sabemos, ha configurado el desarrollo en la civilización occidental: "Respetaba la autoridad de los Sumos Pontífices, pero sabía distinguir entre el sacerdocio y el imperio [...] inflexible en los principios de justicia" (654, p. 236).

En otra dirección, contradiciendo su frecuente celebración de los progresos humanos, retorna a un pensamiento medieval tan característico como el que desprecia la vida terrena frente a la eterna; así medita ante el sepulcro de Don Álvaro de Luna en la catedral de Toledo: "en prueba de cuán pasajera es la gloria del mundo [...] nos gritaría [...] Huid los halagos de la ambición, renunciad a los sueños de una caduca gloria, pensad tan solo en el bien, que jamás se extingue" (645, p. 162).

Aún nos sorprende más un fugaz momento que trasluce una leve duda en la sólida fe de Grassi. Parece mirar al umbral detrás del cual el dolor humano y la propia existencia pueden convertirse en algo absurdo, sin un sentido. Ante el intenso sufrimiento de un personaje (situación casi novedosa en sus artículos), la vida celestial prometida no "es", con la rotunda e incuestionable afirmación habitual, sino que "tiene que ser": "fuerza es pensar que existe una patria, en donde la felicidad comprada con las penas de esta vida, es eterna e inmensurable" (665, p. 324).

Acompañemos ya a Ángela Grassi por sus mundos lejanos y recojamos sus enseñanzas morales, dirigidas en especial a la mitad de la sociedad. 


\section{UN SELECTO INTERLOCUTOR}

En el tercer vértice del estructurado universo ideal de Ángela Grassi se sitúa la mujer, destinataria exclusiva de todos sus artículos ${ }^{8}$, invocada de forma explícita para reclamar su atención o para ofrecerle un consejo moral. Pero no están incluidas todas las mujeres; son los propios vocativos los que restringen y delimitan el grupo de mujeres al que la autora interpela: son "jóvenes casadas" o "jóvenes doncellas", es decir, su mensaje no está dirigido a la mujer mayor, madura, ya formada, sobre la que ejercería más dudosa influencia. Por otra parte, establece con sus destinatarias lazos de proximidad ("tiernas amigas mías", 628, p. 28), con frecuencia tiende a aniñarlas como seres necesitados de guía ("mis queridas niñas" ${ }^{\prime \prime}$ ), lo que eleva la autoridad moral de la autora a la categoría de maestra y hace más efectiva la lección; incluso estrecha los lazos de afecto hasta el nivel de una madre ("mi querida hija", 668, p. 346), que, como es natural, solo busca el bien de sus criaturas.

Pero tales afectos no son un recurso impostado al servicio de la escritora, muy al contrario, parecen nacer espontáneamente de ella misma, porque la mirada de Ángela Grassi vertida sobre el mundo aparece siempre teñida de un apacible y amoroso sentir. Con sus lectoras establece incluso un diálogo directo que interrumpe a veces el discurso o el relato: "como os he dicho en otras ocasiones" (666, p. 331); "ahora quiero hablaros" (ibid.), "voy a contaros" (642, p. 138). Se crea así una corriente de intimidad que aproxima la voz de la autora al discurso de una maestra, o a la tradición del narrador oral.

El grupo de mujeres invocadas se sigue seleccionando por su papel de lectoras ("lectoras mías", 641, p. 132; "amables lectoras del Correo", 643, p.145), es decir, se remite al reducido número de mujeres "letradas" en la segunda mitad del siglo XIX (un $23 \%)^{10}$. Aún más, se trata del selecto grupo de suscriptoras de EI Correo de la Moda, ${ }^{11}$ grupo constituido por mujeres de clases altas, de la burguesía y de la aristocracia, e interesadas no solo en la moda sino en la Literatura. Un grupo verdaderamente selectísimo; mujeres contempladas en un punto como: "flores esbeltas y graciosas que embellecen el jardín humano" (643, p. 145).

Antes de examinar los contenidos de las enseñanzas de Ángela Grassi, interesa conocer el papel asignado a la mujer en el universo ordenado que ella concibe: "ha recibido de Dios "el cetro moral del universo"" (638, p. 107), y aparece "colocada por Dios mismo en el centro de la familia" (626, p. 2). En una sucesión de metáforas explica su responsabilidad: "piloto experto y valiente, ella debe manejar el timón con tal acierto, que libre a la barquilla do se albergan los seres más queridos de su alma, del oleaje de las pasiones tumultuosas y embravecidas que rujen en torno suyo" (ibid., p. 3). O de otro modo, ella es "el pastorcillo que debe responder ante su amo [Dios]", si "dejase que sus ovejuelas triscasen aquí y allá, perdiendo el rico vellón entre las matas, o despeñándose en el embravecido torrente, hasta que por fin fujitivas [sic] y dispersas, fuesen a dar con el lobo carnicero" (ibid.).

De la mujer depende, en consecuencia, todo el orden social desde su función de esposa y madre ("juró al objeto de su amor eterna fe a los pies de los altares, y ciñó con dulce júbilo la diadema santa de las madres" (672, p. 379). Y la sumisión al hombre completa su función; en palabras de la autora: "Todo guarda en la naturaleza un orden admirable [...] el hombre manda, la mujer suplica" (638, p. 107). Las armas de que dispone para realizar su misión son "el candor, la modestia, la bondad, la persuasión, la timidez y la dulzura" (ibid.). Son armas tan poderosas que las mujeres se convierten en: "árbitras absolutas de las pasiones de los hombres, pueden a su antojo hundirlos en el cieno, o elevarlos hasta las regiones inmortales" (645, p. 164). La responsabilidad atribuida a la mujer es de tal trascendencia que la autora invoca en alguna ocasión a los propios padres: "preciso es que abráis los ojos a la luz de la verdad, y que atendáis de aquí en adelante a la educación de vuestras hijas" (ibid., p. 164).

Se completa así la ancestral organización social aceptada por Ángela Grassi en la configuración de su universo literario; consecuentemente, acepta el papel asignado a la mujer, revestida de responsabilidad moral y dependiente del hombre, padre o esposo. Semejante estatus no puede ser cuestionado o perturbado porque pondría en riesgo el perfecto orden universal. ${ }^{12}$

A pesar de su coherencia, una escritora como Ángela Grassi no podía dejar de sentir algunas contradicciones, y hemos de ver más adelante que entreabrió algunas ventanas a la reivindicación social de la mujer.

\section{LOS MUNDOS LEJANOS: FIGURAS HISTÓRICAS FE- MENINAS}

Asumida la importancia de educar a la mujer para sostener el orden perfecto del mundo, la autora despliega en sus textos periodísticos un inmenso saber erudito, histórico y literario, procurando que en evocaciones, descripciones o relatos se encierre una conclusión moral. 
En las muchas decenas de artículos publicados se pueden establecer algunas agrupaciones nítidas y descubrir el orden profundo que se esconde en tan vasto recorrido por el tiempo.

Uno de los grupos más definidos y extensos lo forman las semblanzas de mujeres destacadas a lo largo de la historia, convertidas en arquetipos morales de los que tomar ejemplo. La mayoría son reinas que en su función de esposas o madres de reyes anteponen el bien general al suyo propio: son magnánimas, sacrificadas, devotas y asistidas siempre por la Providencia en momentos decisivos. Dialogan, pactan, persuaden y sufren, pero triunfan y son reconocidas al final: las unas en la tierra, como D. - Sancha de Navarra, símbolo de la constancia, la valentía y la resistencia frente a la desventura ("todos los ecos de Castilla resonaron para ensalzar su nombre [...] para adorar su memoria y bendecirla", 632, p.52); otras triunfan en el cielo, como D. Blanca de Borbón, que sufre el abandono de su esposo Pedro el Cruel, resignándose a su destino con "santa mansedumbre" ("todos Iloraron su muerte [...] viéndola entrar triunfante en la mansión eterna coronada de luz", 628, p.20). Cada una viene a simbolizar un principio moral: como la prudencia y el espíritu de concordia de D. a María de Molina (626); o como la honradez y la defensa valiente de la propia reputación sin renunciar a la libertad de acción, como D. a Blanca de Castilla, reina de Francia y madre de San Luis (654); o como Catalina Cornaro, expresión del amor fraternal y de la renuncia al poder (655); o la reina Vanda de Polonia, que sacrifica su vida para salvar a su país (696).

Algunos modelos proceden de mujeres de la nobleza: como Juana la Beltraneja, que simboliza la resignación frente al destino (683); o como doña Mayor de Fonseca, que representa el amor filial (634).

Otras son famosas emprendedoras que con su trabajo alcanzan la riqueza y procuran un bien social: como Magdalena Didion, que promovió en Nancy las fábricas de encajes creando miles de puestos de trabajo para mujeres (667). Junto a ellas figuran algunas mujeres sabias como las catalanas Isabel de Josa (675) o Juliana Morell (681), o la veneciana Casandra Fedele (687). Entre todas ellas cobra especial relieve Beatriz Galindo, quien en su presentación "ostenta una doble aureola de talento y de virtudes" (641, p. 131), virtudes en las que se centra todo el relato porque hacen nacer su amistad con Isabel la Católica cuando consiguió de ella la gracia para un reo condenado injustamente.

En tan extenso panorama femenino algunas de ellas aparecen en negativo; son contramodelos útiles para advertir de los peligros que es preciso evitar. D. a Juana la Loca es ejemplo de los excesos enfermizos de la sensibilidad y la imaginación "cuando oscurecen la razón con sus vanas quimeras" (647, p. 178). Parecido ejemplo representa D. a Urraca por su volubilidad, "mudando a cada instante de parecer, según las impresiones fortuitas del momento" (651, p. 212), lo que trajo a sus reinos sucesivas guerras y "cuantas calamidades puede producir la civil discordia".

De una manera ambigua aparece la figura de Isabel la Católica en un episodio infantil, cuando niega su ayuda a una pobre familia, horrorizada ante el espectáculo de su miseria ("venciendo el orgullo a la compasión, hizo un gesto de supremo desdén, y se alejó con aire desabrido", 673, p.2); al día siguiente, aconsejada por su ayo, les ofrece arrepentida su protección y "venciendo su repugnancia con admirable fortaleza, tomó al niño en sus brazos, y le meció durante algunos instantes" (ibid.).

Muy especial papel representa la figura de Cristina de Suecia, frente a la cual, más que dibujar un antimodelo, Ángela Grassi lanza un verdadero alegato. Representa la mujer que se rebela contra su condición y piensa, siente y actúa con total libertad e independencia, despreciando los específicos atributos femeninos y rompiendo los límites que la separasen de los hombres en cuanto al ejercicio de la fuerza y la pasión por el estudio y el saber. Semejante figura representa para nuestra autora en todos sus rasgos la mayor amenaza contra el universo ordenado que ella concibe, según venimos viendo. En consecuencia, la reina recibe su castigo y su vida es condenada al vacío y la infelicidad: "Dotada de singular talento y vastísima instrucción, no solo no reportó ningún bien a la sociedad, sino que jamás supo inspirar simpatías" (638, p. 107).

Pero Ángela Grassi va más allá y a la inusual ambición de Cristina opone una humillación casi brutal. Con un hábil recurso lo convierte en realidad en autohumillación porque hace nacer las palabras de la propia conciencia de la reina, que medita: "-Pobre y débil mujer, abandona el cetro por la rueca [...] ¡En vano quieres triunfar de tu propia naturaleza; en vano quieres robar al hombre sus preciados atributos de valor y fuerza! ¡Humíllate, arrástrate a sus pies, que es ese tu destino!" (ibid., p. 108).

Semejantes ideas se desgajan del contexto y se convierten en una tesis demasiado inaceptable para un lector de hoy; aunque en realidad, se trata de un momentáneo exceso que no define exactamente la posición de la autora. Así se demuestra en un artículo posterior 
titulado "La mujer en la Edad Media" (650), en que incluso podríamos hallar aspectos protofeministas.

Como es habitual, Ángela Grassi nos traslada a una Edad Media literaria, al mundo ideal caballeresco del amor cortés que le va a servir como referencia. Un mundo en que las mujeres aparecen elevadas al máximo prestigio y admiración, por lo que "se desarrollaron de un modo admirable las facultades de su entendimiento y las facultades sublimes de su alma" (p. 203). Así enriquecida, la mujer logra ejercer un efectivo influjo civilizador: "por todas partes agita, con férvido entusiasmo, la bandera santa del progreso" (p. 203).

Pero es el hombre el responsable de favorecer este florecimiento de la mujer, porque él impone las leyes: "soberbio y egoísta, se ha reservado para sí solo el monopolio de todas las cosas de la tierra" (p. 202). Esta inesperada acusación contra el hombre, este acto de rebeldía casi único, pero meditadamente elaborado, nos muestra por primera vez a la autora cuestionando el orden perfecto de su universo, y dada la influencia de sus escritos este texto cobra un significado excepcional. No solo cuestiona la posición del hombre, también le atribuye la responsabilidad de que la mujer logre demostrar sus capacidades, que, para mayor asombro, en esta ocasión Ángela Grassi iguala a las del hombre: "Como siempre sucede, entonces fue lo que el hombre quiso que fuera: ingeniosa, galante, ilustrada y heroica. La mayor parte de las damas de la Edad Media, se muestran superiores a sus caballeros en las luces del entendimiento, y a veces tan aptas como ellos en la guerra y en dirigir los grandes negocios del Estado" (p. 203). Así, las capacidades de la mujer son todas y lo reafirma Grassi no como especulación sino como hecho sobradamente demostrado: "Si la mujer es o no apta para llevar a cabo grandes y sublimes hechos, nos lo dice la historia de todos los países en sus páginas eternas" (p. 202).

En una última sorpresa, al final del artículo, la autora se traslada al presente (una de las raras ocasiones) para alzar poéticamente una denuncia y una demanda en favor de la mujer; con solemnes palabras invoca: “iHombres de nuestro siglo! ¡Hoy la mujer es una altísima palmera aprisionada en una maceta de barro, y por esto inclina sus lacias hojas, por esto no da fruto: trasladadla a una tierra fértil, procuradla espacio, y prestará sombra a vuestra frente, y ofrecerá a vuestros labios abrasados un fruto delicioso!" (p. 204).

Grassi desordena así su ordenado mundo con esta explosión controlada de ideas latentes, que humani- zan y acercan su voz, si no a la de su tiempo, sí a la sensibilidad de un lector de hoy. La enorme responsabilidad asumida para educar moralmente a la mujer, hubo de enfrentarla al fin con las limitaciones impuestas a su desarrollo integral y, valientemente, la autora clama reivindicando para ella el despliegue de sus facultades y un mayor papel en la vida social.

Si entre los modelos femeninos evocados la mayoría proceden de la historia de España, las escasas figuras masculinas son tomadas de países tan lejanos como su tiempo y en su mayoría aparecen en compañía de una modélica mujer. Los episodios a que alude tienen referencia real pero los datos son imprecisos y sobre todo se envuelven en la invención literaria. De esta forma, somos trasladados a la Rusia de comienzos del siglo XVII para asistir a la elección de Miguel Teodorovich ${ }^{13}$ como Zar a los 17 años, y a su propia elección como esposa de la humilde y devota Eudosia, para acabar en su buen gobierno, que trajo la paz y la prosperidad a su pueblo: "sus únicos trofeos eran la paz, la abundancia, la virtud, y el creciente desarrollo de las artes y las ciencias" (637, p. 100).

Lejos del ámbito cristiano, pero con semejanza argumental, la autora nos traslada a la China del siglo $\mathrm{X}$, esta vez con llamativa distorsión de datos, ${ }^{14}$ al reinado de Chi-Tsong I, tirano que desposa a la humilde Li-Tsi, quien supera su propia debilidad y apoya con su energía al monarca, transformándolo en justo y bienhechor. Esta vez, junto al mensaje moral aflora una idea social, más o menos latente en otros artículos: la redistribución de la riqueza es impulso de progreso, por lo que "se enriqueció el país, florecieron las ciencias, las artes y la industria" (642, p. 140).

Más legendaria parece la historia del pastor Beppo como descubridor de las ruinas de Herculano, inspirado por su fe en la Virgen de la Esperanza, que de tal modo lo salva de la miseria, la desesperación y el crimen.

Totalmente imaginaria parece la recreación de los amores de Ariosto y Tasso (677), los dos grandes poetas del Renacimiento italiano, cuyas vidas siguieron diverso camino por influjo de sus amadas: el amor sereno y generoso de Alejandra trajo la felicidad al primero, mientras la pasión egoísta de Leonor de Este condenó al infortunio al segundo. De modo que, en realidad, el ejemplo moral lo proporcionan las figuras femeninas.

De estos modelos, el de mayor interés nos lleva hasta la antigüedad clásica a la figura de Demóstenes, al que elige por su magnánima generosidad frente a la 
asechanza de su enemigo Eschino (Esquines, en realidad), y cuya virtud la autora vincula a la cristiana de "perdonar las ofensas". Con la habitual distorsión literaria del hecho histórico, la autora alude al episodio que enfrentó a ambos oradores cuando se propuso la coronación honorífica de Demóstenes por sus servicios a la patria. Esquines levantó su voz oponiéndose, pero fue vencido por el gran orador que respondió con su famoso discurso Pro corona. Lo que en la historia fue lucha entre partidarios y opositores de Filipo de Macedonia, en el artículo es el enfrentamiento entre la envidia de Esquines, que acaba condenado al destierro, y la generosidad de Demóstenes, que lo busca en Rodas para consolarlo y obsequiarlo.

Como es habitual, Ángela Grassi nos lleva hasta algún episodio histórico conocido, para recrearlo libremente, incluso dramatizándolo mediante diálogos imaginarios, según venimos viendo, y para extraer de todo ello una positiva lección moral. En general, los ilustres personajes o los exóticos monarcas sirven más bien para atraer la curiosidad creando una ambientación escenográfica.

\section{LOS MUNDOS LEJANOS: MITOS Y LEYENDAS}

Mayor altura literaria alcanza Ángela Grassi cuando se remonta al mundo de las leyendas, y sobre todo al de la mitología clásica. Podría decirse incluso que en tales textos goza de una libertad creativa que enriquece su estilo.

Así lo parece en el relato de la leyenda medieval de San Lamberto, por cuya intervención el herrero Hullas descubrió el carbón que lleva su nombre. La autora juega con lenguajes casi opuestos para cambiar el enfoque. Al comienzo, presenta la llegada gradual del invierno con un estilo arcaizante y lírico: "agostábanse los postreros frutos del otoño, y la brisa se iba convirtiendo en cierzo, y tras el cierzo asomaban los rudos aquilones que arrebatan a los árboles sus postreras hojas, que arrebatan a la tierra sus postreras flores; que todo lo tronchan y aniquilan, preparando la entrada triunfal del caduco invierno" (657, p. 258). $Y$ hacia el final, cambia el léxico y cambia el ritmo para darnos la ilusión del trepidante mundo técnico recientemente alcanzado: “¡El carbón de piedra, que debía ser de tanta utilidad a la moderna industria, dando impulso a sus máquinas gigantescas; prestando alas a los barcos de vapor para desafiar las tempestuosas ondas de los mares; prestando alas a la soberbia locomotora, que cruza silbando por montes y por valles, triunfando del tiempo y las distancias!" (ibid., p. 260).
El poético origen del canario da lugar a una de las más bellas leyendas, inserta además en una original estructura. Se inicia con el elogio de su canto y nos traslada sin transición a las islas Canarias para pintar un amplio panorama de su naturaleza, imagen del paraíso, y de la primitiva cultura guanche, símbolo de una vida pura y pacífica. La información precisa se funde con el lirismo y con las evocaciones legendarias: “En la hermosa región en donde la fábula coloca el jardín de las Hespérides, y que los antiguos llamaban Islas Fortunatas, por la pureza de su cielo y la fertilidad de la tierra [...]. En aquel tiempo en que Hércules, el héroe predilecto de la fábula, atravesó los desiertos de la Mauritania y se dirigió a estas islas para matar el Dragón que guardaba el jardín de las Hespérides y robar las tres manzanas de oro" (636, p. 91). Con ello se da paso al mito de Cana-Aria, la joven cuyo canto protegía a los guanches de los desastres naturales y a la que identificaban con el "espíritu bienhechor de la montaña". Tras su muerte accidental por olvidarse de cantar, el llanto de los guanches movió a la Naturaleza a transformarla en el canario, el ave de precioso canto. De este modo, el final del artículo regresa en círculo al punto inicial, uno de los muchos ejemplos de eficacia narrativa y del elaborado plan con que Grassi construye sus artículos.

Pero es en los mitos clásicos donde parece encontrar Ángela Grassi sus mundos favoritos: "Las graciosas y poéticas fábulas de la Grecia envuelven siempre una moral suave para el hombre pensador que intenta desentrañarla. Cada una de esas fábulas es un mito, un símbolo delicioso, que antes de persuadir la mente conmueve el corazón. Como su cielo espléndido, como sus campos risueños y floridos, la moral, lejos de mostrarse allí severa y desnuda, se cubre con ligeros velos, se corona de rosas, y pronuncia entre festivas risas sus máximas sublimes" (629, p. 26). La cita encierra un especial interés porque la autora filtra su idea de moral flexible, tolerante, amable, algo que, realmente, prevalece tras la lectura de sus textos, a pesar de ser tan dedicadamente moralizadores.

Algunos de los mitos proceden de Las metamorfosis de Ovidio, como el de Cisne y Faetón, a través del cual canta la belleza del ave y compone un encendido elogio de la amistad como uno de los mayores tesoros.

Con recurso más original recoge el mito de Alciona (Alcíone) y Ceix, símbolo del amor conyugal, transformados por los dioses en alciones ${ }^{15}$ para perpetuar su unión. El relato se inserta dentro de otro en que un narrador oral recurre al mito para explicar que la presencia del ave haciendo su nido es anuncio de mar en 
calma. Algunas descripciones nos traen ecos de sabor clásico: "Acercábase el crepúsculo con sus medias tintas, y aves, brisas, insectos y sonoros ecos, iban enmudeciendo por grados, entregándose al bienhechor descanso de la noche" (656, p. 250).

Aún nos recuerda la autora el estrecho vínculo entre el mito y la realidad, para reforzar su valor: "Esto dice la tradición, y aunque fabulosa, el hecho es eterno e inmutable" (ibid., p. 252).

El punto más alto de su recorrido por la mitología, en realidad, una verdadera cumbre dentro del conjunto de sus artículos, lo alcanza la autora con una serie que titula "Las cuatro majestades". De los siete artículos que la componen ${ }^{16}$, los dos primeros sirven de marco y narran una historia atemporal envuelta en sucesos heroicos y mágicos, protagonizados por la devota y compasiva Alsina. En su peregrinar es llevada a un "vergel ameno" ante cuatro personajes, para decidir cuál de ellos es superior en majestad y más digno de rendirle culto.

Desde este punto, en los cuatro artículos siguientes Alsina es solo un pretexto para que las cuatro divinidades que personifican las cuatro fuerzas elementales de la naturaleza se describan a sí mismas, componiendo cada una de ellas un espectáculo apoteósico: Eolo, como "rey de los vientos" (660); el sol, representado con sus nombres en distintas culturas, y símbolo de "la luz, el calórico y el fuego" (661); el "Dios del agua", sin un nombre definido, porque abarca todas sus manifestaciones, no solo el mar (662); y también sin nombre, una mujer representa "la madre tierra" (663).

Con el despliegue de argumentos que cada uno alega en su favor, la autora nos aproxima al centro del debate de los filósofos presocráticos de Mileto, para dirimir cuál de los elementos naturales constituía la fuerza primordial.

Pero lo más extraordinario es la deslumbrante fusión que realiza entre explicaciones científicas en torno a cada elemento y la presencia constante de alusiones míticas y culturales. Se genera así una dinámica alternancia de lenguajes adaptados a cada enfoque.

Por una parte, Ángela Grassi expone con estilo sobrio y objetivo la información científica de los fenómenos naturales; así la explicación de un eclipse: "El eclipse se efectúa cuando la luna, que es un cuerpo opaco y naturalmente oscuro, hallándose situado en línea recta, o casi directa entre el sol y la tierra, oculta al primero, y arroja sobre la segunda, en medio del día su sombra tenebrosa" (661, p.291); así la compo- sición del agua: "Uno de los principales constitutivos del agua, es una sustancia aeriforme, mucho más lijera [sic] que el aire inflamable, que se llama hidrógeno; la otra es una sustancia también simple, esencial a la respiración, pero incombustible, que se llama oxígeno, y sin el cual perecerían todos los seres animados" (662, p. 300); o así la atracción de la tierra: "Los sabios te habrán dicho sin duda, que es la ley de la gravedad la que hace que la fruta desprendida del árbol caiga al suelo" (663, p. 306); o así el ciclo hidrológico: "La atmósfera recibe en su seno a una porción considerable de vapores y exhalaciones que se desprenden de los mares, de los ríos y de la tierra, y después de haberlos purificado, se los devuelve en forma de lluvia bienhechora" (660, p. 282). Incluso son citados científicos como Lavoisier y Newton ${ }^{17}$.

En forma paralela fluye en los textos la visión mítica de la naturaleza, expresada con lenguaje extraído de la tradición cultural. De este modo son identificados los vientos según su procedencia: "Euro o Levante, el que viene de Oriente; Noto o Auster, el de Mediodía; Bóreas o Tramontana, el del Septentrión, y por último, Favonio o Céfiro, el de Poniente" (660, p. 282). Envuelto el lenguaje en elementos más subjetivos se invoca al sol y su adoración a lo largo de la historia: "iEsplendoroso sol, fuego brillante, yo fui el emblema de la divinidad increada, ante el cual doblaron la rodiIla los sencillos pueblos primitivos! [...] iAquellos hombres pasaron, pero aunque menos tierno, jamás carecí de culto! ¡Homa en Persia, Agni en la India, Apolo en Atenas, Mithra en Roma, y Sol en la virgen América, por do quiera fui objeto de amor, veneración y asombro!" (661, p. 290). Y con una subjetividad más íntima y sentimental, es evocada la primitiva adoración de la tierra: "Los pastores de la Arcadia, de costumbres puras y sencillas, me adoraban únicamente a mí, y transmitieron su culto a Atenas, a Tebas, a la Grecia entera, en donde yo era invocada bajo el nombre de Ceres, la piadosa madre. iCeres, la bondad increada, que ama del mismo modo al hombre que a la planta, y al insecto de alas de oro! iCeres, la madre universal!" (663, p. 306).

Aún superpone nuestra autora otro lenguaje impregnado de lirismo en el que triunfan sus propias emociones, y que irrumpe sin cesar entre los otros lenguajes. Así expresa la pura exaltación: "iLa luz! iLa luz!... ilmagen perfecta de la inmortal belleza!” (661, p. 291). Y exclama ante la inmensidad del mar: " $i O h$, grandeza incomparable! ¡Quién podría describir la majestad de esos profundos mares! [...] i Los mares! ¡Espejos del cielo! ¡Arcanos incomprensibles!" (662, p. 299). 
Con emoción épica se desata el viento: "A mi voz braman los huracanes, corren de mar en mar, de clima en clima, amontonando las nubes, suscitando las tormentas, y haciendo crujir con su salvaje empuje los quicios de la tierra" (660, p. 282). Con emoción íntima se percibe el sonido: "Escucha ese concierto de ecos perdidos, rumores vagos y lejanos, armonías de las aguas, cantos y susurros de pájaros e insectos" (660, p. 283). O con emoción melancólica, el hombre siente la llegada del otoño: "en las poéticas tardes del Otoño divaga por la campiña, hollando las hojas secas de los árboles, que antes le servían de dosel, y ya le sirven de alfombra, mostrándole cuán pronto caducan los bienes de la tierra" (662, p. 299).

Aún se entrelazan en el discurso de la autora algunas ideas relevantes, como la del valor de la palabra, adoptando un tono de sentencia: "la palabra es la gran civilizadora de los pueblos" (660, p. 283).

También adquiere especial relevancia la reflexión inserta como lamento de la tierra, agredida por el progreso tecnológico del hombre: “iEs verdad que a veces me arranca quejidos dolorosos la brutalidad del hombre, cuando rompe mis entrañas para construir canales y mudar la dirección de las aguas, o cuando abate mis altivos montes para abrir paso a la locomotora, que corre veloz devorando los espacios! ¡Oh, sí, sufro mucho entonces; pero me someto y callo!" (663, p. 307). Vemos que, momentáneamente, el discurso atemporal puesto en boca de una naturaleza personificada se traslada al presente de la autora, a la sociedad tecnológica del XIX, y nos transmite una naciente inquietud por el daño que la mano del hombre inflige a la tierra, y que ha perdurado agravada hasta nuestros días.

En suma, Ángela Grassi nos ofreció con esta serie de artículos un documento de la amplitud de su pensar y su sentir, un testimonio de que ciencia, cultura y lirismo convivían en su concepción de la realidad, y demostró su capacidad para fundir tan distintas visiones en un todo armonioso.

Aún añadió al conjunto un breve artículo a manera de epílogo, en el que Alisia rechazaba adorar a ninguna de las cuatro fuerzas naturales, sobre las que prevalecía la suprema majestad de Dios, "oculta, sabia e infinita" (664, p. 314). El epílogo carece de valores literarios, pero ponía el broche para devolvernos al habitual universo de la autora.

Así se cierra este capítulo donde hemos entrevisto el que tal vez sea más atractivo "mundo lejano" creado por Ángela Grassi.

\section{LAS CREACIONES HUMANAS Y EL CONOCIMIENTO DE LA NATURALEZA}

Hablábamos al principio de dos grandes direcciones seguidas por Ángela Grassi en el desarrollo de su obra. La primera la venimos recorriendo y constituye el ancho caudal de sus enseñanzas morales, fundadas en los diferentes modelos históricos y míticos. La otra dirección, mucho menos amplia, es la celebración de todo lo creado, que incluye la naturaleza y las creaciones humanas, todas de origen divino en el universo de Grassi ya descrito.

Entre ambos caminos existen, como es natural, zonas comunes, elementos compartidos de lección y de celebración, pero fijaremos ahora la atención en los artículos dedicados al estudio de aquellas creaciones humanas que han significado un gran progreso social, o encierran un especial valor para la vida humana.

Por otra parte, en toda la obra de Grassi están presentes, junto a las creaciones de su imaginación, los estudios eruditos más diversos, pero es en los artículos ahora seleccionados donde cobra el protagonismo la información documental.

Hay un cambio en la intención de la autora, que sigue invocando a sus lectoras para atraer su atención, pero ahora pretende sobre todo instruir, más que moralizar.

La variopinta temática de estos artículos permite algunas agrupaciones que gradúan el significado de fondo. De tal manera, la aludida celebración de lo existente dirige su foco en primer lugar a las ciudades, como punto de partida de la civilización: "El progreso nació con el mundo [...] erigió su trono entre los que derribaron los troncos de los árboles para formar la primera aldea" (698, p. 202).

Ciudades que testimonian la evolución social con su esplendor monumental y que van dejando su huella en el tiempo. Elige Antioquía, descrita desde su geografía hasta sus usos culturales, para reflejar el grado de progreso alcanzado, aunque: "La descripción de una ciudad cualquiera de aquella remota época, bastaría a dar a conocer su ilustración" (ibid.). Otras ciudades, como Persépolis, Palmira, Nínive o Babilonia, son evocadas y descritas de forma más o menos fabulosa, ${ }^{18}$ añadiendo una nota moral sobre la fugacidad que reflejan sus ruinas: " $\mathrm{iAl}$ evocar los nombres de las ciudades que un tiempo fueron espléndidas y florecientes, convertidas hoy en un montón de escombros, el alma comprende la insensatez del humano orgullo, cifrado en obras frágiles y perecederas" (627, p. 11). La autora abarca desde el conocimiento libresco de las ciudades antiguas hasta la experiencia de la ciu- 
dad visitada, y así describe Portici, crecida junto a las ruinas de Herculano, con toda su belleza sensual: "allí acuden [...] a pedir sombra a sus bosques, aromas a sus pensiles, murmurios a la brisa y a las aguas que riegan los vergeles" (648, p.186).

La ciudad culminante es Salamanca, en cuya visión parecen fundirse el conocimiento histórico y el espacio conocido, incluso sentido: "Hay ciudades venerandas, a cuyo solo nombre se estremece el alma de respeto, creyendo ver surgir de sus antiguos y denegridos muros las sombras de mil ilustres héroes, de mil inspirados vates, de mil sabios, lumbreras de la ciencia y gloria de su patria. En su recinto augusto todo recuerda su presencia" (641, p. 130).

Desde la celebración de esta ciudad, "madre de las artes y las ciencias", según cita Grassi, podemos continuar el recorrido hacia un grupo de artículos que hablan de lo que llamaríamos industrias o trabajos de valor artístico, como la fabricación de encajes o de perlas artificiales, cuyo origen y desarrollo explica de forma novelada. O como las obras de ebanistas ("que trabajan el ébano") y escultores, con repaso histórico de su origen, sus figuras y los materiales empleados. 0 como la moda, nacida con la sociedad humana, de la que Grassi ofrece un prolijo panorama de transformaciones y modelos, desde los sombreros hasta el calzado (633). De todas ellas elogia el progreso material que las ha acompañado, y añade una nota social en cuanto a los puestos de trabajo que han proporcionado a las clases populares: "los hombres ocupados en preparar el vidrio, las mujeres y los niños en ensartar las perlas" (“Las perlas de Venecia”, no 640, p. 124).

Pero atraen mucho más la atención los artículos dedicados a los grandes inventos humanos, empezando por la escritura, cuya historia traza la autora desde su origen remoto, pasando por pueblos y culturas con su diversidad de signos, siguiendo por los soportes materiales hasta el comienzo del papel, del que detalla sus sistemas de fabricación sucesivos para acabar repasando los instrumentos de escritura hasta la pluma de acero. Este curso decreciente del artículo se inicia intensamente con una valoración subjetiva: “iNada más sorprendente que la escritura! ¡Nada hay en el universo más útil, ni que eleve más al hombre sobre cuantos seres le rodean! [...] ¡Palabra mágica, [...] eco que resonará de siglo en siglo [...]; por ella no se ha roto jamás la invencible y misteriosa cadena del progreso!" (630, p. 34).

Casi como continuación vino tiempo después el artículo "Las bibliotecas", para ocuparse de la literatura y de los sistemas para "transcribir y multiplicar" las obras escritas. Desde la evocación de las perdidas bibliotecas de Alejandría y Constantinopla, la autora se aproxima a la labor de los monjes copistas de la Edad Media, cuando el saber se refugió en los conventos, y el proceso que siguió con la multitud de amanuenses contratados por las universidades del siglo XIV, hasta llegar a la invención de la imprenta como respuesta a una necesidad: "si crecía el número de los copistas, crecía de una manera asombrosa el de los lectores. La fiebre del saber se había comunicado rápidamente a todas las inteligencias" (653, p. 227). Después de repasar algunos antecedentes de la imprenta, eleva su homenaje a Gutenberg: "no es un hombre; ies la personificación del progreso, es el símbolo de un grande acontecimiento, que ha franqueado el paso a la civilización" (ibid.). Pero ve los peligros que trae la fácil difusión para sembrar "ideas infames y desorganizadoras". Un peligro acrecentado por el nacimiento de los periódicos, a cuya historia retrocede de nuevo la autora para recordar las "actas diurnas" creadas por César en Roma, y el nacimiento de los primeros periódicos: en Francia, con la Gazzeta (en realidad, La Gazette), de 1631; y en España, con el Diario de Avisos, un siglo posterior.

Se cierra este artículo fundamental con una defensa de estirpe ilustrada: la necesidad de las bibliotecas, pero pequeñas, llevadas incluso a cada aldea, "si se quiere que el progreso moral e intelectual sea un hecho positivo" (p. 228). Muy cerca se sitúa aquí Ángela Grassi de las corrientes regeneracionistas que se están agitando en su época.

Otros inventos son celebrados con entusiasmo por nuestra autora, como la litografía, cuyo origen y proceso técnico inserta en un relato convencional; o como la fotografía, cuya génesis explica con más rigor recordando los nombres que participaron en el proceso, desde Porta, descubridor de la cámara oscura, hasta Daguerre y sus seguidores. Admirada, la autora celebra como una conquista reciente la aproximación a realidades lejanas que la imagen fotográfica posibilita: "iHoy el joven, ansioso de instruirse [...] puede admirar, sin moverse de su aposento, los bellos edificios de París, Londres, San Petersburgo y Constantinopla, hasta en sus detalles más leves e insignificantes!" (666, p. 332). Y el joven, obviamente, se identifica con la propia autora.

Nos instala así Ángela Grassi en la celebración del progreso técnico que había traído su siglo XIX, un homenaje que culmina en su artículo "Tiempos antiguos y modernos", verdadera excepción dentro de su labor que nos lleva sobre todo al presente con algunos re- 
trocesos al pasado. Se trata de un texto fundamental en que repasa la transformación de las costumbres que ha traído el progreso técnico. Se abre con el efecto del alumbrado urbano, cuando al atardecer, antes hora de recogimiento, nos lanzamos "a la calle en busca de placeres tumultuosos, a las calles inundadas de luz, casi remedo del sol brillante, en donde vaga una multitud, ya inquieta y apresurada [...] o ya negligente y ociosa" (649, p. 194). La escena se completa con algunos ingredientes inquietantes, como "el ruido de los infinitos coches" o los gritos de mujeres y niños "que venden periódicos y fósforos". Pero en la comparación con el pasado el saldo es positivo: "el aspecto que ofrecían en su tiempo estas mismas calles, mudas, lúgubres y oscuras, iluminadas tan solo a largos trechos por la lámpara que ardía delante de la capillita de una Virgen" (ibid.). Fiel a su método, la autora retrocede para explicar la historia del alumbrado en las ciudades europeas con amplio despliegue de datos.

El mismo proceso sigue con el empedrado de las calles, enlazando así los distintos fenómenos ("El progreso se forma por medio de un encadenamiento de adelantos simultáneos"), y retrocediendo de nuevo, pasa por las calzadas romanas, las calles embaldosadas de la Córdoba califal, sigue por las ciudades de Europa con las fechas de sus pavimentos, e incluso alude a técnicas y materiales. De igual modo, describe los vehículos desde los primitivos carros de la antigüedad, pasando por los carruajes de distintas épocas, hasta describir la amplia variedad de modelos y tipos de servicio de los coches de su tiempo, e incluir la llegada del tren circulando por la ciudad.

Al final triunfa expresamente en el artículo la alabanza del progreso y de la nueva sociedad: "iDichoso siglo el nuestro, en el cual cada mañana al abrir los ojos se ofrecen a nuestra consideración nuevas y estupendas maravillas!" (p. 196).

Una alabanza que se amplía en el artículo "La ciencia antigua" a otros inventos, que describe sin darles nombre: "no se pensaba en que un poco de agua, reducida a vapor, pudiese dominar los vientos, devorar las distancias y suplir el trabajo de millares de brazos en los ferro-carriles y las fábricas de tejidos [...] en que, aprisionando el rayo, se pudiese transmitir la chispa eléctrica y con ella el pensamiento de un polo al otro polo [...], y lo que es más importante aún, en destruir el dolor, suspendiendo la sensualidad física durante las crueles operaciones de la cirugía" (698, p. 203). Magnífica forma sintética de explicar el inmenso adelanto de la anestesia, así como el de la máquina de vapor y el telégrafo.
Pero Ángela Grassi, en una imagen perfecta de sí misma, dividida entre la ciencia y su fe religiosa, exclama: "Oh!, siglo diez y nueve, si fueras tan creyente como sabio, si fueras tan honrado como luminoso" (649, p. 196). Es decir, la autora teme la amoralidad con que puede avanzar la ciencia y defiende unos principios o valores humanos que para ella solo pueden estar garantizados dentro de un sentido trascendente de la existencia, dentro de la fe.

\section{LA REALIDAD, EL PRESENTE, EL YO, EN SOMBRAS}

Regresamos ahora de todas las lejanías recorridas en el tiempo en busca del presente, en busca de algún testimonio de las realidades cercanas a Ángela Grassi. Y nos encontramos sobre todo una realidad desaparecida: desaparecidos los conflictos políticos de un tiempo tan cambiante como la segunda mitad del siglo XIX;19 desaparecidas las grandes concepciones científicas que llevaron al profundo conocimiento de la naturaleza y del hombre (tan solo encontramos las aludidas menciones del progreso técnico $)^{20}$; desaparecidos los profundos conflictos entre las clases sociales que avanzan en una espiral creciente; ${ }^{21}$ desaparecidos el dolor, la enfermedad, la injusticia, la miseria, el mal, que no existen sino como concepto global; y sobre todo, desaparecidas las mujeres reales, no solo en el plano sociológico, en el que han empezado a cuestionar los estrechos límites a que son reducidas, sino también en el plano de la literatura, donde tantas heroínas son fiel reflejo de la insatisfacción de la mujer burguesa en la moderna sociedad, un testimonio que, como sabemos, se inicia desde mediado el siglo con la flaubertiana Madame Bovary, y se despliega en el mismo tiempo de nuestra autora.

Nos ofrece a veces atisbos de realidad, pero estilizada, depurada de toda huella vital. Los innumerables personajes de sus artículos, sean históricos o imaginarios, aparecen como arquetipos sin conflicto, carentes de matices psicológicos, de los que interesa solo la virtud o el error que simbolizan.

Rara vez mencionados, en muy leves alusiones están presentes los pobres: "el desmantelado tugurio del pobre" frente a "los salones del rico" (636, p. 91); "los mineros [...] esclavos, casi desnudos" (640, p. 122). Muy pocos de sus personajes surgen de la pobreza, pero siempre es una pobreza muy estilizada, a veces elegida, como la que vive Eudosia con su padre en la paz del campo, antes de convertirse en zarina (637, p. 98). O la que sufre Lidia, la niña misérrima, que en Venecia recibe de la Virgen el secreto de la fabricación de perlas, con lo que alcanza la riqueza. 
Igualmente, son premiados, y por fin enriquecidos por su virtud y trabajo, el pastor Beppo, el herrero Hullas o la encajera Didion.

En muy pocos momentos la autora nos muestra un cuadro popular como experiencia directa, pero de nuevo nos oculta la sociedad real porque solo aparece inmersa en celebraciones festivas; así sucede en Aranjuez, cuando la autora presencia la romería de San Isidro: "En su derredor también se colocan los vendedores de los gráficos torrados, rosquillas y frasquetes, y acuden en tropel de todos los pueblos vecinos los alegres labradores, montados los unos en jamelgos, los otros en carros, y los otros a pie, llevando la merienda en un pañuelo, atado en la punta de su bastón de viaje, lo cual ofrece el conjunto más animado y pintoresco que puede imaginarse" (643, p. 146).

Este afán de depuración de la realidad afecta a la propia autora, que apenas alude a sí misma, que esconde pudorosamente su yo. En cuanto a sus experiencias más vivas, solo conocemos que visita Aranjuez en mayo de 1866 (ibid.), que desde allí viaja en tren a Toledo, donde recorre la catedral y donde asiste a la festividad del Corpus. En su larga descripción de cuanto descubre y presencia se mezclan sucesivas efusiones de admiración o estados de emoción, pero solo nos ofrece junto a ello una auténtica vivencia, la llegada y la partida de Toledo: "Volaba silbando la locomotora y en muy breve tiempo nos hallamos delante de las ruinas cubiertas de musgo"; "Cerraba ya completamente la noche, las campanas de la catedral dejaron oír su sonoro y majestuoso tañido, como un solemne adiós de despedida; silbó la locomotora, y volvimos a Aranjuez" (645, pp.162 y 164).

Muy poco más; de pasada alude a su presencia en una reunión, sin otras precisiones, donde se debate sobre la ciencia moderna. Y en una evocación, nos conduce a su infancia, a un paseo junto al mar: "yo recorría la orilla del Mediterráneo en la bella y pintoresca Cataluña [...] Una tarde salí a recoger conchas con otras jovencillas, mis amigas, y nos sentamos al pie de una encina que crecía en la misma ribera [...] Era aquella una magnífica tarde de verano" (656, p. 250).

En cuanto a su yo personal, al margen de las frecuentes efusiones subjetivas, solo afirma de sí misma dos ideas: una de ellas, reiterada alguna vez y confirmada a lo largo de este estudio, es una sincera verdad: "como sabéis que soy tan amiga de viejas historias" (643, p. 146). La otra, no es sino una prudente precaución, desmentida por el mismo estudio: "Yo, pobre e ignorante mujer". Nos sorprende la autora con esta negación de sí misma, que lleva a meditar sobre su significado, en todo caso refleja un temor a ofrecer una imagen demasiado erudita. ${ }^{22}$ Sin duda, es este el origen de otro fenómeno observado en sus artículos, las referencias a sus fuentes de información son siempre vagas e imprecisas: "dice uno de nuestros antiguos y célebres escritores" (626); "dice un viajero célebre" (627); "un escritor francés" (638); "dicen todos los historiadores" (654); "según refieren crónicas añejas" (651); "en los archivos de la Catedral [de Santiago]" (634). Pero pasa de soslayo sin dejar ver las fuentes consultadas ${ }^{23}$.

En absoluto, pobre mujer, y mucho menos, ignorante; sí es posible que en la frase se encuentre la razón por la que construyó su mundo literario al margen de la realidad; tal vez huyó de ella porque podía añadir otros peligros al hecho de ser una mujer intelectual, y prefirió cautelosamente poner a resguardo el paso adelante que significaba su obra literaria.

Lo cierto es que Ángela Grassi solo entreabre rendijas sobre la realidad, y su mundo queda preservado casi por completo en una suave penumbra del pasado.

\section{SU MUNDO Y SUS LENGUAJES}

Como reflejo último de este mundo literario en que nos hemos adentrado están los lenguajes, que nos alejan de lo cercano y cotidiano y nos devuelven a la lejanía.

Para construir su mundo ideal, la autora adopta un tono elevado y culto, ennoblecido, de retórica a veces excelsa, expresión de belleza y bondad, de afectos puros, de placeres del espíritu. Se apoya, según hemos venido viendo, en un léxico escogido y rico, salpicado de cultismos o de arcaísmos, al tiempo que acoge algunas expresiones técnicas novedosas ("globos aerostáticos"); y juega sin cesar con simetrías, metáforas y símiles. ${ }^{24}$

Sobreabundan las valoraciones y juicios subjetivos, efecto con frecuencia de una gran exaltación ("Las Catedrales! Epopeyas sublimes de los siglos, ¿quién habrá que no os cante y no os admire?") ${ }^{25}$. Exclamaciones e interrogaciones retóricas se suceden generando un estado emotivo, porque se trata de llegar a las lectoras invocadas para provocar en ellas una reacción emocional: "iLos pájaros! ¿Quién no admira esos pequeños seres alados que nos embriagan de delicias con sus cantos, que nos asombran con su prodigioso instinto?" (671, p. 370).

El retoricismo conduce en ocasiones a una expresión convencional y caduca: "iQuién sabe si entre 
estas bellas jovencillas, alguna hurí de ojos azules o negros grabará con mano trémula un nombre querido en la corteza de uno de aquellos árboles seculares!" (643, p. 145). Pero muchas veces nos ofrece originales efectos, como la llegada de un cortejo convertida en sonido: "Al día siguiente los tranquilos ecos del valle iban repitiendo, y transmitiéndose los unos a los otros, el murmullo de muchas voces, y el ruido que producían los corceles de una numerosa y brillante cabalgata que atravesaba sus estrechas sendas" (637, p. 100). Y en muchas ocasiones alcanza un aliento de belleza clásica: "Acercábase el crepúsculo con sus medias tintas, y aves, brisas, insectos y sonoros ecos, iban enmudeciendo por grados, entregándose al bienhechor descanso de la noche" (656, p. 250).

Para atraer al lector a su mundo ideal y hacer este más próximo y verosímil, lo interpela a menudo con invocaciones e interrogaciones, que son recursos clásicos del narrador oral ("¿Lo has oído?"; "Ayer os hablaba"; "Acabo de deciros") y crean una impresión de diálogo cercano entre la autora y sus lectores.

Ya hemos visto ejemplos en que Grassi desciende para describir brevemente, con sobria objetividad, algún elemento real, pero resulta muy sorprendente descubrir que con plena voluntad traza una leve pincelada naturalista: "el triste aspecto de sus ruinas cubiertas de asquerosos insectos y musgo amarillento". ${ }^{26}$ Este adjetivo despectivo nos sitúa en las antípodas de la visión idealista y romántica que ella misma nos ha dado con su canto a los insectos (670), y la ennoblecida visión de las ruinas que nos ha dado en otros textos.

No obstante, los diferentes lenguajes de Grassi se hallan, al igual que los mundos que expresan, muy lejos de realismos y naturalismos, los lenguajes y las tendencias dominantes en su tiempo.

En cuanto a la construcción de los artículos, en su mayoría están basados en una estructura semejante, con diversas variantes: una anécdota, una breve reflexión o la descripción de cualquier objeto, fenómeno o creación sirven a la autora para plantear un tema que esconde un significado moral; desde ese punto se retrocede al pasado, con frecuencia para introducir un relato que ilumine el tema propuesto y cuyo desenlace contenga una enseñanza moralizadora. A veces la enseñanza es el elemento introductorio y el relato viene a confirmar con su moraleja la tesis inicial. El elemento fijo es el salto atrás, pero a veces el relato es sustituido por un recorrido histórico que despliega el tema inicial en su evolución (669). Otras veces se encadenan anécdotas a relatos en una estructura digresiva $(651,667)$; en otras se inserta un relato dentro de otro $(640,643)$. Incluso introduce un relato en una vivencia recordada (656).

Y dentro de las narraciones insertas se introducen sin cesar dramatizaciones de episodios intensos, con diálogos inventados, tanto para los personajes imaginarios como para las figuras históricas.

La autora pone en juego todos los recursos intensificadores que puedan captar el interés del lector y dotar de mayor eficacia a sus enseñanzas.

El conjunto reúne en sí un asombroso caudal de sabiduría literaria.

\section{A LO LEJOS, SIGUIENDO SU CAMINO}

El universo perfecto de Ángela Grassi que hemos descrito y analizado hasta aquí revela su obra como una nueva elaboración neoplatónica, que solo atiende a ciertos reflejos de la realidad, contemplándola de lejos, en el fondo, defendiéndose de ella, sin poder evitar algunos atisbos de contradicción y de inquietud, como evidenciaba sobre todo su celebración del progreso técnico, unida a su temor por la amenaza de “desespiritualización” del ser humano.

Ante las dicotomías, triunfa siempre en ella la defensa apasionada del sentimiento religioso, lo que la sitúa plenamente en la corriente neocatólica ${ }^{27}$ que en la segunda mitad del siglo XIX extendió su influencia frente a la corriente positivista dominante en el panorama científico, intelectual y artístico, y frente a la ideología liberal. ${ }^{28}$

Pero su afán de saber, su inmensa curiosidad por los procesos culturales históricos, por el progreso que los ha acompañado y por el creciente conocimiento del hombre sobre la naturaleza se confunden en su imaginario adornados por el mito y la leyenda. Un gran esfuerzo intelectual guiado por la personalidad sobria, imaginativa y mesurada de nuestra autora.

Trabajó con prudencia y coherencia dentro de un mundo organizado, jerarquizado para el predominio del hombre, y dejando atisbos de su deseo de algo más, de abrir un hueco para la mujer en el espacio del que era excluida.

Así, buscaba entrar en el mundo mental de las mujeres de las clases altas sin inquietarlas, deslizando el interés por el saber, introduciendo valores morales y culturales, accesibles, amenos, tranquilizadores, pero abría puertas para poder anhelar algo más. Fue la 
suya una obra sincera y hábil al tiempo, que supone un eslabón sólido para la evolución de la mujer que se avecina.

En realidad, dedicó su obra a potenciar los valores del ser humano, a elevarlo, algo que, desde diferentes creencias e ideologías, debe ser reconocido. Ese mensaje no está tan lejos del que podría proponer un espíritu menos religioso, incluso un espíritu laico que sueñe con una humanidad perfeccionada, generosa y fraterna, gobernada por grandes valores. Hoy sería un punto axial en que se podría compartir el esfuerzo de alcanzar esa humanidad de "hombres humanos", evocando las palabras de César Vallejo.

\section{NOTAS}

1 Todos los artículos consultados y no citados en este trabajo revisten las mismas características temáticas y formales y solo confirman las conclusiones de nuestro análisis. A partir de 1867, la autora tiende a sustituir los artículos por poemas y por capítulos de novelas por entregas, que publica el El Correo de la Moda, y que editó también en forma de libro. Para la búsqueda de los textos ha sido imprescindible guía la conocida obra de M. a del Carmen Simón Palmer (1991).

2 Nos hace recordar De los nombres de Cristo, de Fray Luis de León, autor que figura entre sus lecturas predilectas.

3 Para evitar la acumulación de notas, todas las citas de los artículos llevarán indicado entre paréntesis el número de El Correo de la Moda en que aparecen, según se relaciona en la Bibliografía, y el número de página.

4 Sus artículos se agrupan en sección dentro de El Correo de la Moda, bajo el rótulo "Instrucción".

5 Sánchez Llamas (2000) ha descrito el universo literario de las escritoras pertenecientes al llamado "canon isabelino", que Á. Grassi contribuyó a construir junto a otras escritoras como Pilar Sinués.

6 [San Luis] "era devoto sin ser supersticioso. Protegía al clero pero no se dejaba dominar por él" (654, p. 236).

7 Alude a la destrucción de bibliotecas antiguas: Alejandría, Constantinopla (653, p. 226).
8 Grassi es "escritora para mujeres" (Ruiz Silva, 1990).

9658 , p. 266; 667, p. 338; 671, p. 371.

10 La propia Grassi, hacia 1841, pertenecía al exquisito $2 \%$ de la población femenina española que sabía leer y escribir. Recordemos al respecto los datos sobre alfabetización de la población española y su evolución en el siglo: 1841 - Alfabetizados 24\% (39\% H, 9\% M). Sabían leer: $22 \% \mathrm{H}$ y $7 \% \mathrm{M}$. Leer y escribir: $1 \% \mathrm{H}, 2 \% \mathrm{M}$. En Inglaterra el $60 \%$, en Francia el $80 \%$.

1877 - Alfabetizados 34\% (45\% H, 23\% $\mathrm{M}$; grandes diferencias provinciales, Madrid 73\% H, 50\% M.

1900 - Alfabetizados 44\% (se estanca). Atraso de dos siglos, en Francia $45 \%$ en 1675.

11 Existía una fórmula de suscripción para modistas, atentas en especial a figurines, patrones y bordados.

12 El universo literario de las escritoras isabelinas como Grassi ha sido ampliamente estudiado en su significado sociológico (Blanco, 2001).

13 Se trata de Mijail Feodorovich, que fue el primer Zar de la dinastía Romanov.

14 La torre de Nankín citada en el texto data del siglo $\mathrm{XV}$, muy posterior al tiempo aludido en el relato. Por otra parte, ChiTsong I, el emperador, fue también muy posterior (1507-1521). En la fecha señalada en el relato era emperador Muzong (951-969). Es muestra de la libertad con que Grassi maneja los datos históricos.
15 El alción, más conocido como "martín pescador".

16 Aparecieron en El Correo de la Moda en números sucesivos, desde el $n=658$ hasta el no 664, entre el 16 de septiembre y el 31 de octubre de 2013. El título que los reúne se incluye bajo otro epígrafe más amplio titulado "Cartas sobre la educación", que abarca en total doce artículos.

17 Dentro del epígrafe "Cartas sobre la educación", se añaden otros artículos en que predomina el afán de divulgación de aspectos de la naturaleza: sobre los insectos (carta XII, no 670); sobre los pájaros (carta XII [bis, debía ser XIII], no 671).

18 Nínive, por ejemplo, es descrita con 1.500 torres y 70 millones de habitantes.

19 Solo se localiza una alusión política, y alude a un tiempo anterior: "la horrible persecución política que en aquella época [reinado de Fernando VII] sufrieron los liberales" (643, p. 147).

20 Parecida idea suscitan sus novelas: "Para Ángela Grassi el verdadero camino del progreso no se halla en la lucha de clases, el racionalismo científico, el positivismo..., la única vía posible es aquella que dimana del principal precepto cristiano: amor al prójimo" (Ayala, 2005, p. 61).

21 Aunque la autora deja ver la idea social cristiana que se inclina hacia el pobre, quien mira jubiloso al "Juez justo", mientras el poderoso siente terror frente al "Juez incorruptible" (645, p. 163). 
22 Recordemos el apelativo vulgar de "marisabidilla" dedicado a la mujer culta.

23 A pesar de incluir a veces citas marcadas como textuales, no nos da la referencia: "La regencia de esta princesa, en circunstancias tan difíciles, dicen todos los historiadores a la par, hizo honor a su sexo; fue..." (654, p. 235).

24 También es frecuente el galicismo que antepone artículo a los nombres de países: "La Grecia”, incluso "La Europa". Igualmente abundan los laísmos: "salvarla la vida"; "la cubrían las manos". En cuanto a la ortografía, es muy caprichosa: "uracanes", "estremo", "magestades", etc; a veces, sin duda, erratas de imprenta.

25 “Recuerdos de Toledo" (no 645, p. 163).

26 "Cartas sobre la educación" (VIII, no 666, p. 332).

27 El Neocatolicismo fue un movimiento político e ideológico de la España de la segunda mitad del siglo XIX, que intervino activamente en la vida política, muy cerca del Partido Moderado y del Tradicionalista. Durante la Restauración alcanzaron gran influencia en los gobiernos, lo que se manifestó sobre todo en la denominada cuestión universitaria.

28 Sánchez Llamas (2001) destaca de Grassi: "haber textualizado las premisas estéticas de la Alta cultura isabelina" ( $p$. 108).

\section{BIBLIOGRAFÍA}

Ayala, M.Á. (2005). “Ángela Grassi, del romanticismo al dualismo moral". Anales de Literatura Española 18, pp. 53-64.

Balmaseda, J. (1883). "Ángela Grassi”. El Correo de la Moda, 36, p. 282.

Blanco, A. (2001). Escritoras virtuosas: narradoras de la domesticidad en la prensa isabelina. Granada: Universidad de Granada.

Coronado, C. (1850). "Galería de las poetisas. Ángela Grassi". La Ilustración, 17, pp. 2-3.

Coronado, C. (1858). "Galería de poetisas contemporáneas. Doña Ángela Grassi”. La Discusión, 721, p. 3.
Coronado, C. (1861). "Galería de poetisas contemporáneas. Doña Ángela Grassi”. La América, 6, pp. 12-13.

Cuenca Lucherini, V. (1859). "Señorita doña Ángela Grassi". El Mundo Pintoresco, 5, pp. 34-35.

Huerta Posada, R. de la (1896). "La mujer. Ángela Grassi y Techi". El Álbum Ibero Americano, 15, pp. 176-177.

Ruiz Silva, C. (1990). «Ángela Grassi: una aproximación». En Escritoras románticas españolas. Madrid: Fundación Banco Exterior, pp. 155-166.
Sánchez Llamas, I. (2000). «Nostalgias del Antiguo Régimen y conciencia burguesa de crisis. Ángela Grassi de Cuenca (18231883)». En Galería de escritoras isabelinas. La prensa periódica entre 1833 y 1895. Madrid: Cátedra, pp. 251-291.

Sánchez Llamas, I. (2001). Antología de la prensa periódica isabelina escrita por mujeres (1843-1894). Cádiz: Universidad de Cádiz.

Simón Palmer, M.C. (1991). Escritoras españolas del siglo XIX. Manual bio-bibliográfico, Madrid: Castalia.

\section{ARTÍCULOS CITADOS DE EL CORREO DE LA MODA:}

La mujer prudente, 626, 8-I-1866, pp. 2-4.

Lo que nos dicen las ruinas, 627, 16-I-66, pp. 11-13.

Un sueño, 628, 24-I-66, pp. 18-20.

El cisne, 629, 31-I-66, pp. 26-28.

La escritura, 630, 8-II-66, pp. 34-35.

La verdadera grandeza, 631, 16-II-66, pp. 42-44

Doña Sancha de Navarra, 632, 24-II-66, pp. 50-52.

La Moda, 633, 8-III-66, pp. 66-68.

Da. Mayor de Fonseca, 634, 16-III-66, pp. 74-76.

El ave amiga del hombre, 636, 31-III-66, pp. 90-92.

El grano de jenabe, 637, 8-IV-66, pp. 98-100.

Cristina de Suecia, 638, 16-IV-66, pp. 107-108.

Las perlas de Venecia, 640, 30-IV-66, pp. 122-124.
Lauros y rosas, 641, 8-V-66, pp. 130-132.

La torre de porcelana, 642, 16-V-66, pp. 138-140.

Revista semanal, 643, 24-V-66, pp. 145-147

Recuerdos de Toledo, 645, 8-VI-66, pp. 162-164

La fiesta del Corpus en Toledo, 646, 16-VI-66, pp. 170-172.

Da. Juana la Loca, 647, 24-VI-66, pp. 178-180.

La Virgen de la Esperanza, 648, 30-VI-66, pp. 186-188.

Tiempos antiguos y modernos, 649, 8-VII-66, pp. 194-196.

La mujer en la Edad Media, 650, 16-VII-66, pp. 202-204.

Los haces de trigo, 651, 24-VII-66, pp. 210-212.

La Providencia, 652, 31-VII-66, pp. 218-220

Las bibliotecas, 653, 8-VIII-66, pp. 226-228.

Blanca de Castilla, 654, 16-VIII-66, pp. 234-236.

El amor fraternal, 655, 24-VIII-66, pp. 242-244. 
¡Dos en uno!, 656, 31-VIII-66, pp. 250-252.

La urna de oro, 657, 8-IX-66, pp. 258-260.

Cartas sobre la educación. Las cuatro majestades I, 658, 16-IX-66, pp. 266-267.

Cartas sobre la educación. Las cuatro majestades II, 659, 24-IX-66, pp. 274-275.

Cartas sobre la educación. Las cuatro majestades III, 660, 30-IX-66, pp. 282-283.

Cartas sobre la educación. Las cuatro majestades IV, 661, 8-X-66, pp. 290-291.

Cartas sobre la educación. Las cuatro majestades V, 662, 16-X-66, pp. 298-300.

Cartas sobre la educación. Las cuatro majestades VI, 663, 24-X-66, pp. 306-308.

Cartas sobre la educación. Las cuatro majestades. Epílogo, 664, 31X-66, pp. 314-315.

Cartas sobre la educación VII, 665, 8-XI-66, pp. 322-324.

Cartas sobre la educación VIII, 666, 16-XI-66, pp. 330-332.
Cartas sobre la educación IX, 667, 24-XI-66, pp. 338-340. Cartas sobre la educación X, 668, 30-XI-66, pp. 346-347. Cartas sobre la educación XI, 669, 8-XII-66, pp. 355-356. Cartas sobre la educación XII, 670, 16-XII-66, pp. 362-363. Cartas sobre la educación XII (repetido, sería XIII), 671, 24-XII-66, pp. 370-371.

La chimenea, 672, 31-XII-66, pp. 378-379.

La adoración de los reyes, 673, 8-I-1867, pp. 1-2.

Isabel de Josa, 675, 24-I-1867, pp. 18-19.

Dos amores, 677, 8-II-1867, pp. 34-36.

La maravilla de Cataluña, 681, 8-III-1867, pp. 66-67.

La resignación, 683, 24-III-1867, pp. 83-84.

Casandra Fedele, 687, 24-IV-1867, pp. 114-116.

El ángel de Polonia, 696, 30-VI-1867, pp. 186-188.

La ciencia antigua, 698, 16-VII-1867, pp. 202-204. 